\title{
A novel methodology to regain sensitivity of quick
}

\section{clay in a geotechnical centrifuge}

\author{
Gertjan Meijer and Jelke Dijkstra
}

\begin{abstract}
A novel reconstitution process is developed to reconstitute remoulded quick clay with comparable sensitivities to the sampled undisturbed material. This laboratory method is based on scaling some of the main in-situ processes involved in the development of sensitivity in a natural quick clay. It is shown that high sensitivity can be regained in a sequence of scaled flocculated sedimentation stages followed by consolidation and leaching in a geotechnical centrifuge. The suggested approach is a promising method for fast reconstitution of sensitive clay samples for element and physical model testing in the geotechnical laboratory.
\end{abstract}

Key words: reconstitution, sensitivity, structure, quick clay, flocculation, leaching, geotechnical centrifuge.

\section{Introduction}

Sensitive marine clays cover a wide area of North America, Europe and Asia. Recent quick-clay landslides in Norway and Sweden, which blocked major transportation links, demonstrate the hazards that sensitive marine clays can pose to the society. Systematic study of the failure mechanisms of these slides on field scale would be prohibitively expensive with large uncertainties in test conditions and test control. Hence, the study on model scale in controlled conditions in the laboratory would offer many advantages. The latter requires the ability of the reconstitution of quick clay with similar properties in the laboratory.

Quick clay is characterised by a high sensitivity $S_{t}$ (ratio between the undisturbed and remoulded shear strength). Using

G.J. Meijer. University of Dundee, Division of Civil Engineering, Geotechnical Engineering research group, Dundee DD1 4HN, United Kingdom

J. Dijkstra. ${ }^{1}$ formerly Delft University of Technology, now Chalmers University of Technology,Department of Civil and Environmental Engineering, SE-412 96 Göteborg, Sweden

${ }^{1}$ Corresponding author (e-mail: jelke.dijkstra@ chalmers.se). the Swedish definition, it is defined as material with a sensitivity exceeding 50 and a fully remoulded shear strength smaller than $0.5 \mathrm{kPa}$ (Rankka et al. 2004). These clays behave like a liquid after remoulding, due to the loss of structure and the high water content. This change of material structure during remoulding is irreversible. Therefore, a special reconstitution method is required if sensitivity is to be regained.

Only very few researchers have tried to reconstitute sensitive clays. Bjerrum \& Rosenqvist (1956) reconstituted remoulded Norwegian quick clay by deposition in salt water $\left(35 \mathrm{gl}^{-1}\right)$ for two months, followed by 3 months of consolidation under a load of to $240 \mathrm{kPa}$ and finally leaching the sample under an applied vacuum during 18 months. This process obtained a clay with a sensitivity of 70-180. Pusch \& Arnold (1969) investigated the effect of leaching by reconstitution of illite powder in sea water with a salinity of $35 \mathrm{gl}^{-1}$. The illite was first treated with peroxide to remove organic material and subsequently oven dried. However, after consolidation and leaching in a geotechnical centrifuge the sensitivity was increased from 2.1 to only 3.7 , hence not representing quick clay.

Despite of the limited success in the past, a reconstitution method which obtains high sensitivity is still required, e.g. to 
obtain samples with high sensitivity for probing the constitutive behaviour in element tests or validation of theoretical models for quick clay on the boundary element level in geotechnical centrifuge tests. One advantage of such a method is the flexibility it offers for creating reconstituted samples of any shape without sample disturbance. Secondly, it reduces the need for expensive sampling associated with large samplers with minimal sample disturbance. Thirdly, the ability to create undisturbed reconstituted samples of natural clay would allow to systematically investigate sample disturbance effects and allow the (re-)use of poor quality samples for research.

In the present study a novel method is developed which improves upon previous attempts, i.e. addressing the duration and effectiveness of the method. This paper introduces the experimental methodology and discusses the preliminary results.

\section{Methodology}

\subsection{Natural development of sensitivity in quick clays}

The natural development process of quick clays in the northern hemisphere is taken as a starting point. The main clay mineral in the natural Scandinavian quick clays is generally illite, while the amount of swelling clay minerals is very low or non-existent. Furthermore, a large fraction (up to 50-60\%) of finely ground (e.g. by glacier movement) primary minerals (quartz, feldspar) is present (Bjerrum \& Rosenqvist 1956, Brenner et al. 1981, Rankka et al. 2004, Geertsema \& Torrance 2005, Mitchell \& Soga 2005). To overcome problems originating from the influence of mineralogy, in the present study a natural Swedish quick clay sampled at a depth of 6-12 $\mathrm{m}$ in the Gothenburg area, is used. Some characteristics of this material are presented in Table 1.

During deposition of natural quick clays, individual clay platelets stick together forming flocks in the presence of cations (e.g. in saline sea water). Inter-particle attraction is enhanced by decreasing the size of the diffuse double layer. These larger and heavier flocks settle more rapidly than individual clay platelets, resulting in random stacking of flocks with a high macro-porosity (Van Olphen 1963, Hunter 1993, Sposito 1989). The ability to reflocculate after remoulding will be reduced when the salinity of the sediment is reduced after being consolidated, e.g. in a low ionic concentration environment. The inability to reflocculate will result in very low disturbed strengths. In natural conditions, this reduction of ions can result from leaching (either by ground water flux or diffusion) once the sediment is lifted above sea level by isostatic uplift following deglaciation, or by binding of the ions by dispersing agents (Söderblom 1966 , Crawford 1968, Torrance 1974, Torrance 1979, Brenner et al. 1981, Rankka et al. 2004).

\subsection{Simulating natural genesis in the laboratory}

The proposed laboratory reconstitution consists of three steps: sedimentation, consolidation and leaching. Each of these processes is scaled in the laboratory, in order to reduce the time scale and/or enhance its effect on the resulting sensitivity.

In the laboratory, flocculation can be readily enhanced by 1) increasing the cationic charge (by increasing the ionic concentration and/or cation valence), 2) decreasing the $\mathrm{pH}$, or 3) adding an optimal amount of flocculation enhancing polymers. Increasing the salinity decreases the size of the diffuse double layer, hence enhancing inter-particle attraction. Decreasing the acidity changes the clay particle edge charge from a negative to a positive charge, enhancing flocculation by edge-toface attraction (Van Olphen 1963). Finally, addition of polymers could link several clay platelets together to one polymer chain, thus forming a larger 'particle' (Bergaya et al. 2006).

Consolidation of the sediment to a representative in-situ stress level can either be imposed by application of an (an)isotropic stress in an element test, or by increasing the gravitational acceleration in a geotechnical centrifuge. The latter has the additional advantage that a slurry can be used from the start, which is especially beneficial considering the liquid state of the remoulded quick clay.

Leaching might be performed by inducing a fresh water flux 
through the sample driven by an hydraulic head difference, by diffusion, by application of electro-osmosis or by a combination of these.

In the presented experiments, flocculation is enhanced by changing the salinity of the water. This method is preferred, because the influence is known to be reversible during leaching. Demineralized water and pure $\mathrm{NaCl}$ are used. Although higher valence cations would be more effective, small amounts of these ions adverse sensitivity development when not thoroughly leached. Therefore, sodium ions are preferred to simplify the leaching process. Small scale sedimentation and consolidation experiments are performed in perspex tubes, with 14 $\mathrm{mm}$ inner diameter and a height of $150 \mathrm{~mm}$, to study the influence of the initial water content of the slurry, salinity and the order of mixing of clay, water and salt.

The high salinities (up to $\approx 250 \mathrm{gl}^{-1}$ ) used affect both the volume and density of the water. Therefore, expressing salinity in common terms of grammes per litre water will induce inaccuracies when the salinity of the salt water is to be measured. Hence, in the following the salinity $s$ is calculated in terms of mass rather than volume, and is defined as the ratio of grammes of salt over grammes of pure water, expressed in promille. As a rule of thumb, a salinity of $1 \%$ approximately corresponds with $1 \mathrm{gl}^{-1}$.

Initial small scale flocculation experiments showed that using oven-dried clay, which is subsequently ground with pestle and mortar and pluviated in salt water, proved to be detrimental for the development of high void ratios. Segregation by particle size was clearly visible during sedimentation at $1-\mathrm{g}$. Therefore, in all subsequent experiments a clay slurry created from 'wet' (non oven-dried) clay is used instead. The mixing sequence of salt, water and clay has no significant impact on the void ratio. Variation of the water content $w$ of the slurry between $300 \%$ and $1600 \%$ (expressed as the ratio of pure water mass and oven-dried clay mass) at a salinity of $s=350 \%$ o shows that the water content should be higher than approximately $500 \%$ to prevent gelation in the slurry. Increasing the salinity from 0 to $250 \%$ at $w=500 \%$ shows increasing void ratios after 1 -g sedimentation with increasing salinities (the used dried clay mass is $1.35 \mathrm{~g}$ ). The void ratio at $s=250 \%$ o is almost double the result of the $s=0 \%$ tests. In the small scale tests, the height of the flocculated sediment is measured with a ruler with a 0.5 $\mathrm{mm}$ division and an estimated measurement accuracy of 0.1 $\mathrm{mm}$. This results in accuracies in void ratio of approximately \pm 0.03 .

The influence of salinity is further studied in the test tubes during $\mathrm{N}-\mathrm{g}$ consolidation (in a geotechnical centrifuge). During the centrifuge test, grayscale images (1260 x 972 px) are acquired. Subsequently, sediment heights are determined from these images using a customized edge-finding algorithm. This procedure is estimated to yield accuracies in void ratios of 0.3 (corresponding with $1 \mathrm{~mm} / 10 \mathrm{px}$ ) when lighting was poor, which was the case in some of the tests in Figure 1. In most centrifuge tests however, lighting was much better, resulting in more accurate void ratio results $( \pm 0.03,0.1 \mathrm{~mm} / 1 \mathrm{px})$.

Centrifuge consolidation test results (Figure 1) show that, as is the case at $1-\mathrm{g}$, increasing salinities increases the void ratio. The highest consolidation rate occurs at $s=31 \%$. It appears that at this concentration an optimum exists between flocculation, which increases the rate by increasing flock mass, and a decrease in settling velocity caused by both the increase in fluid viscosity and the decreased effective particle weight (higher fluid density) in more saline water.

The effect of the loading rate on the consolidation behaviour is studied by varying the acceleration ramp up to a maximum value corresponding with 87-g, see Figure 2. Although the differences in the relative time versus void ratio plot suggest buildup of excess pore water pressures, the loading rate does not influence the final void ratio.

Tests with conditions resulting in reconstituted clay with the highest void ratio $(w>500 \%, s=250 \%$, using non-oven dried clay, loading rate unimportant) are scaled up to $50 \mathrm{~mm}$ di- 
ameter samples. The clay slurry is first normally consolidated in $160 \mathrm{~mm}$ high perspex tubes under self weight at $87-\mathrm{g}$, and subsequently under an overburden load of $\Delta \sigma_{v}^{\prime}=55 \mathrm{kPa}$, resulting in $25 \mathrm{~mm}$ high samples with an average void ratio of $2.3 \pm 0.1$. Subsequently, these samples are leached from top to bottom using demineralized water, using a falling head with a maximum water pressure of $28 \mathrm{kPa}(\Delta H=130 \mathrm{~mm}$ at $22-\mathrm{g})$. In this stage the acceleration is reduced and the sand overburden removed to ensure that the whole sample is only loaded in recompression. Simultaneously, a second benchmark sample is 'leached' with salt water $(s=250 \%$ o) under the same water pressure gradient. The latter benchmark test accounts for the possible strength changes from solely the water flux.

The development of water level and hydraulic conductivity in time are presented in Figure 3 for one fresh and one salt water leaching test. In saline samples, the hydraulic conductivity is seen to decrease in time. This can be explained by the decrease in pore water salinity, increasing the double layer sizes and therefore impeding water flow. The increase in permeability in salt water leached samples might be explained by effective stress relief in the upper parts of the sample. The amount of leached salt is determined by measuring the mass of the residue after oven drying the salt leachate. Test results are presented in Table 2. Leaching by diffusion, although the sample was allowed to leach for 3 consecutive weeks and the demineralized water refreshed every 2 or 3 days, did not decrease the salinities to sufficiently low values (order of $2 \mathrm{gl}^{-1}$ ) for the development of sensitivity (Torrance 1974).

\subsection{Strength and sensitivity results}

Laboratory vane and fall cone tests are used to investigate the strength and sensitivity of the undisturbed and the reconstituted natural quick clay samples. The results are presented in Figure 4. The reconstituted samples have higher void ratios but lower sensitivities, compared to the undisturbed natural material. The results for reconstituted samples and samples leached with salt water show that the water flow as applied in the cur- rent tests does not influence the strength. In the current experiments leaching however decreases both the undisturbed and the disturbed strength significantly and increases the sensitivity up to a ratio exceeding 100 . Pictures of the reconstituted leached sample are presented in Figure 5. In these can be seen that the material behaves liquid-like after remoulding, proving that the characteristic remoulded quick clay behaviour is artificially recreated.

When salt is added to the remoulded material, the strength, measured with a lab vane test, increases from $\approx 0 \mathrm{kPa}$ to 0.9 $\mathrm{kPa}$ between $s=20$ and $40 \%$. When the salinity is further increased to $250 \%$ o the strength slowly increases to $1.4 \mathrm{kPa}$.

\section{Discussion and Conclusions}

These preliminary experiments show that sensitivity can be regained in a reconstituted quick clay using the presented methodology. Although very weak compared to the undisturbed natural material, the reconstituted material meets the Swedish definition of quick clay. However, the developed method still needs to be optimized and validated for other quick clays. Although, besides the influence of salinity, water content and consolidation, no comprehensive testing programme is adopted to systematically find the optimal conditions, the results are promising for further research.

A major advantage of the concept is that it is a relatively fast method. Reconstitution of $25 \mathrm{~mm}$ high samples took 2 days to consolidate and 10 days to leach. Reconstitution of larger samples with this method will still be a lot faster than prior attempts, because of the favourable scaling conditions in the geotechnical centrifuge. However, the reconstituted strengths are still low and the void ratios are still rather high, compared to the void ratios in the original material.

Further research will therefore focus on increasing the stress level during consolidation in order to create a reconstituted material which has strengths and void ratios which are more comparable to the natural clay. Additionally, the mechanical prop- 
erties of the material should be studied in more detail when more sample material is reconstituted. Furthermore, other means for enhancing consolidation and leaching such as e.g. electroosmosis should be investigated. Finally, approaching sensitivity from a colloid chemistry and thermodynamic perspective will give more insight in sensitivity development and material structure, which in turn gives enhanced possibilities for modelling and selection of optimal reconstitution conditions.

\section{Acknowledgements}

The support of J.J. de Visser from Delft University of Technology in constructing the test setup and executing the tests is greatly acknowledged. The original quick clay material was kindly donated by P. Hedborg and M. Olsson from Chalmers University of Technology.

\section{References}

Bergaya, F., Theng, B., \& Lagaly, G. (2006). Handbook of clay science. Amsterdam: Elsevier.

Bjerrum, L. \& Rosenqvist, I. (1956). Some experiments with artificially sedimented clays. Géotechnique 6, $124-136$.

Brenner, R. P., Nutalaya, P., Chilingarian, G. V., \& Robertson, J. O. (1981). Soft Clay Engineering, Chapter 2, pp. 159-240. Elsevier.

Crawford, C. (1968). Quick clays of eastern Canada. Engineering Geology 5, 239-265.

Geertsema, M. \& Torrance, J. K. (2005). Quick clay from the Mink Creek landslide near terrace, British Columbia: Geotechnical properties, mineralogy, and geochemistry. Canadian Geotechnical Journal 42, 907-918.

Hunter, R. J. (1993). Introduction to modern colloid science. Oxford: Oxford University Press.
Mitchell, J. K. \& Soga, K. (2005). Fundamentals of soil behavior, 3rd edition. Hoboken, New Jersey: John Wiley \& sons, inc.

Pusch, R. \& Arnold, M. (1969). The sensitivity of artificially sedimented organic-free illitic clay. Engineering Geology 3, 135-148.

Rankka, K., Andersson-Sköld, Y., Hulten, C., Larsson, R., Leroux, V., \& Dahlin, T. (2004). Quick clay in Sweden, report 65. Technical report, Swedish Geotechnical Institute, Linköping.

Söderblom, R. (1966). Chemical aspects of quick-clay formation. Engineering Geology 1, 415-431.

Sposito, G. (1989). The chemistry of soils. Oxford University Press.

Torrance, J. K. (1974). A laboratory investigation of the effect of leaching on the compressibility and shear strength of Norwegian clays. Géotechnique 2, 155173.

Torrance, J. K. (1979). Post-depositional changes in the pore-water chemistry of the sensitive marine clays of the Ottawa area, eastern Canada. Engineering Geology $14,135-147$.

Van Olphen, H. (1963). An introduction to clay colloid chemistry, for clay technologists, geologists and soil scientists. New York: John Wiley \& sons inc. 
Table 1. Material characteristics of the used natural quick clay.

\begin{tabular}{lllll}
\hline \multirow{2}{*}{ Parameter } & Unit & \multicolumn{3}{c}{ Sample } \\
\cline { 3 - 5 } & & 1 & 2 & 3 \\
\hline Sampling depth & {$[\mathrm{m}]$} & 6 & 10 & 12 \\
$\rho_{\text {bulk }}$ & {$\left[\mathrm{kgm}^{-3}\right]$} & $1.54 \cdot 10^{3}$ & $1.58 \cdot 10^{3}$ & $1.69 \cdot 10^{3}$ \\
$\rho_{\text {grain }, \text { pycnometer }}$ & {$\left[\mathrm{kgm}^{-3}\right]$} & 2697.5 & & 2709.6 \\
$w$ & {$[\%]$} & 75.1 & 71.9 & 49.5 \\
$w_{L}$ & {$[\%]$} & 57 & & 48 \\
$w_{P}$ & {$[\%]$} & 28 & 27 & 20 \\
$s_{u, f a l l ~ c o n e}$ & {$[\mathrm{kPa}]$} & 19.4 & 30.6 & 32.8 \\
$s_{u r, \text { vane }}$ & {$[\mathrm{kPa}]$} & 0.26 & 0.22 & 0.17 \\
$S_{t}$ & {$[-]$} & 75 & 139 & 240 \\
\hline
\end{tabular}

Table 2. Void ratio and salinity results before, during and after the leaching experiments. The void ratios are calculated by measuring the sediment volume and the measured amount of added clay particles and particle density $\rho=2700 \mathrm{kgm}^{-3}$.

\begin{tabular}{|c|c|c|c|c|c|c|c|}
\hline \multicolumn{3}{|l|}{ Leaching } & \multirow{2}{*}{$\begin{array}{l}\text { None } \\
2.42\end{array}$} & \multirow{2}{*}{$\begin{array}{l}\text { Hydraulic } \\
\text { fresh water } \\
2.31\end{array}$} & \multirow{2}{*}{ head, } & \multirow{2}{*}{$\begin{array}{l}\text { Hydraulic head, salt } \\
\text { water } \\
2.26\end{array}$} & \multirow{2}{*}{$\begin{array}{l}\text { Diffusion } \\
2.45\end{array}$} \\
\hline Before & $e_{0}$ & {$[-]$} & & & & & \\
\hline & $m_{\text {salt }}{ }^{2}$ & [g] & 6.20 & 7.57 & & 7.53 & $5.74^{4}$ \\
\hline & $w^{2}$ & [\%] & 78.8 & 76.2 & & 76.9 & 74.5 \\
\hline \multirow[t]{2}{*}{ After phase 1} & $e$ & {$[-]$} & - & 2.44 & & 2.33 & \\
\hline & $\Delta m_{\text {salt }}^{3}$ & {$[\mathrm{~g}]$} & - & 6.81 & & $\approx 0$ & \\
\hline \multirow[t]{3}{*}{ After phase 2} & $e$ & {$[-]$} & - & 2.32 & & 2.33 & 2.24 \\
\hline & $\Delta m_{\text {salt }}{ }^{3}$ & {$[\mathrm{~g}]$} & - & 0.60 & & $\approx 0$ & $?^{5}$ \\
\hline & $w$ & [\%] & - & $82.8^{1}$ & & $78.5^{2}$ & $?^{5}$ \\
\hline
\end{tabular}

${ }^{1}$ Calculated assuming that $s=0 \%$

${ }^{2}$ Calculated assuming that $s=250 \%$ o

${ }^{3}$ Determined by oven drying of the leachate (majority of the leached salt) and water still on top of the sample (salt leached out by diffusion)

${ }^{4}$ Sample was trimmed to a height of $19.3 \mathrm{~mm}$ so it could be applied in an oedometer at a stress of $\sigma_{v}^{\prime}=2.5 \mathrm{kPa}$. Therefore the total mass of salt is lower than in the other tubes

${ }^{5}$ Amount unknown, varying results with different methods 


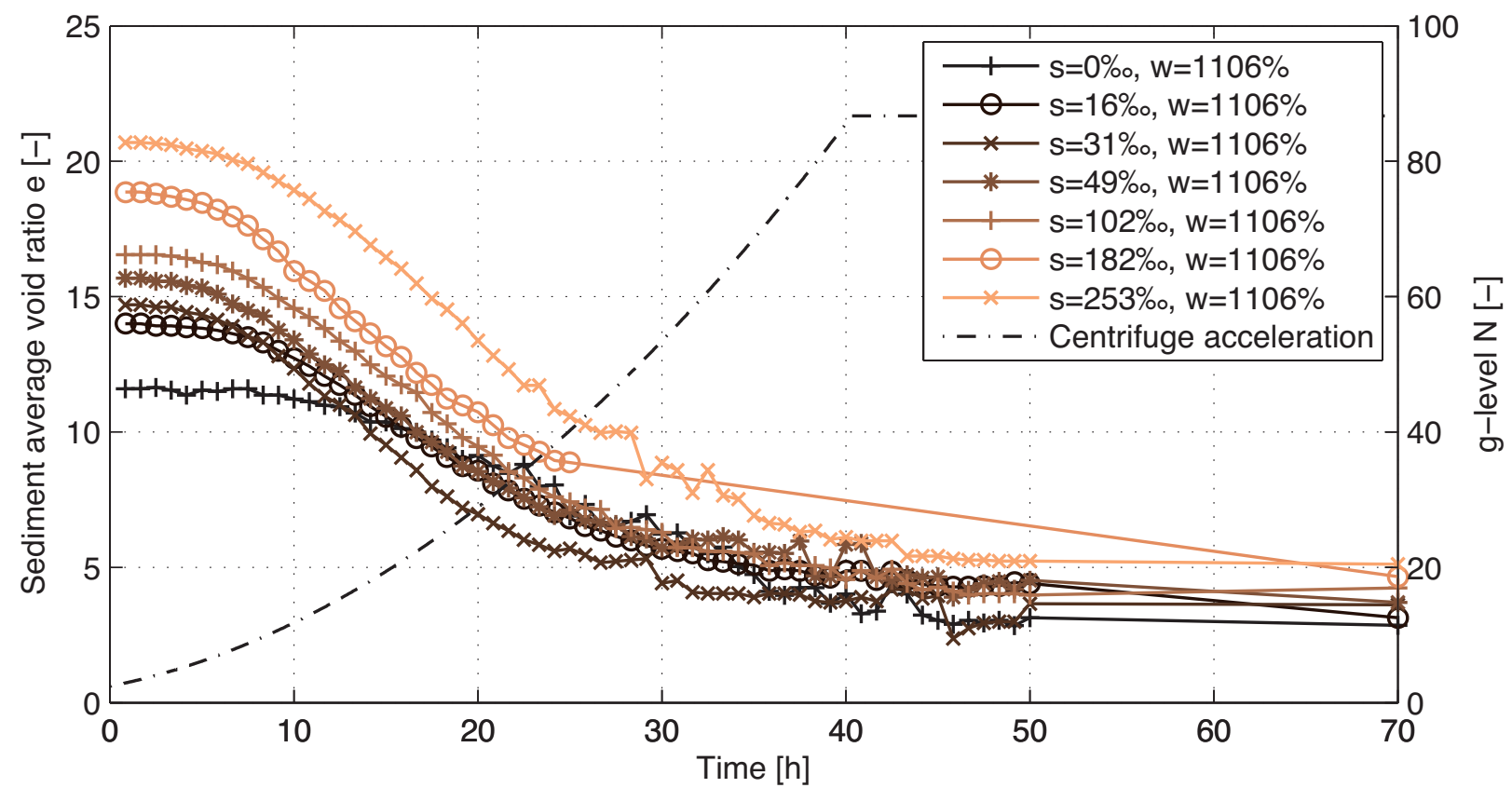

Fig. 1. Influence of salinity on the void ratio of $\mathrm{N}-\mathrm{g}$ consolidated samples under self weight. Approximately $1.35 \mathrm{~g}$ of pure clay is used in each test.

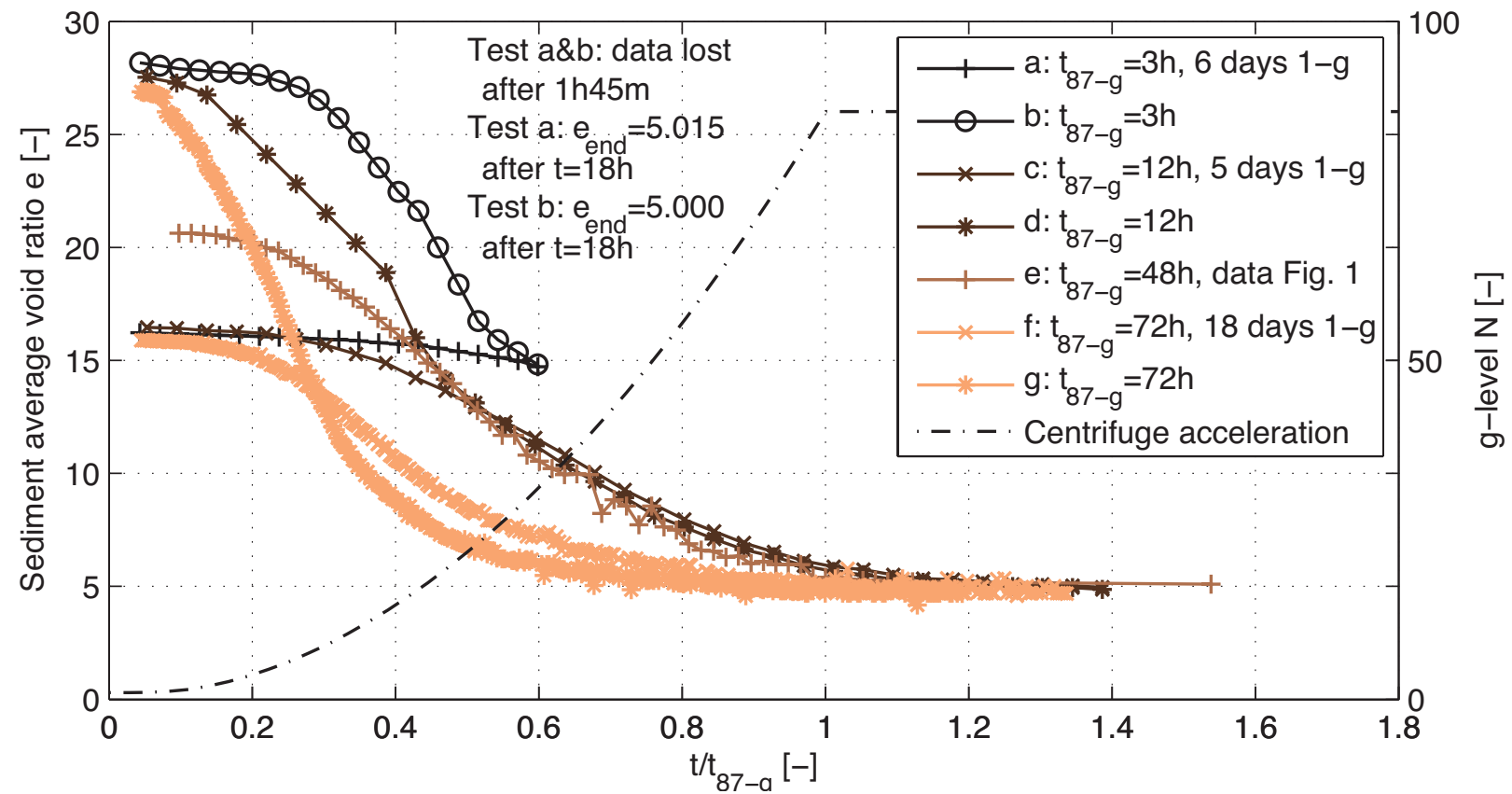

Fig. 2. Influence of centrifuge acceleration rate on the void ratios of the salt-clay-water mixture with a salinity of $250 \%$. Samples are load under self weight, so that $\sigma_{v, \max }^{\prime}=4.8 \pm 0.1 \mathrm{kPa}$ (effective stresses are corrected for the increased density of the salt water). A final void ratio of $e=5$ corresponds with a sediment height of approximately $22 \mathrm{~mm}$. 


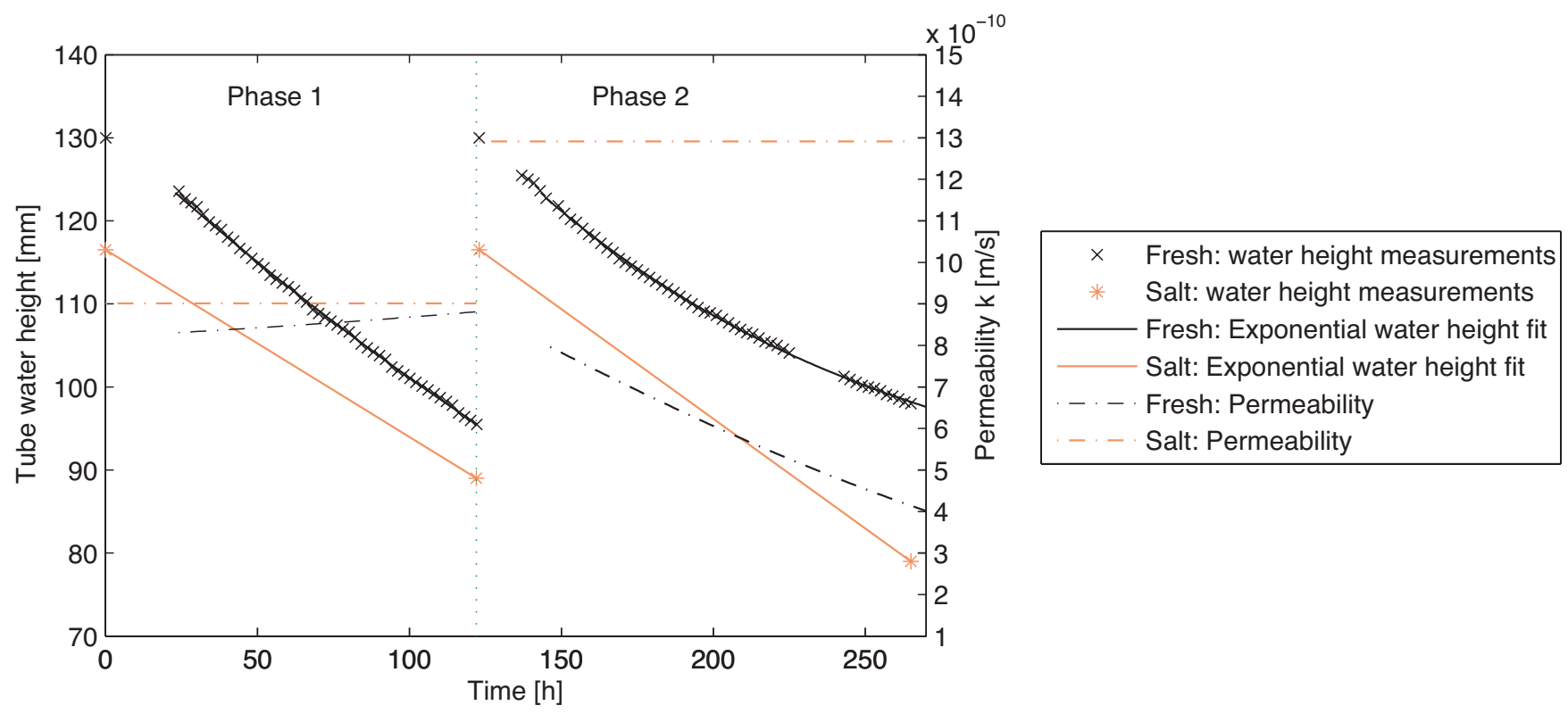

Fig. 3. Development of water height and hydraulic conductivity in time during leaching at 22-g. Halfway the leaching process the water level in the cell is raised to the original level to enhance leaching rates. The initial water height in the salt water leaching test is lower to compensate for density differences.
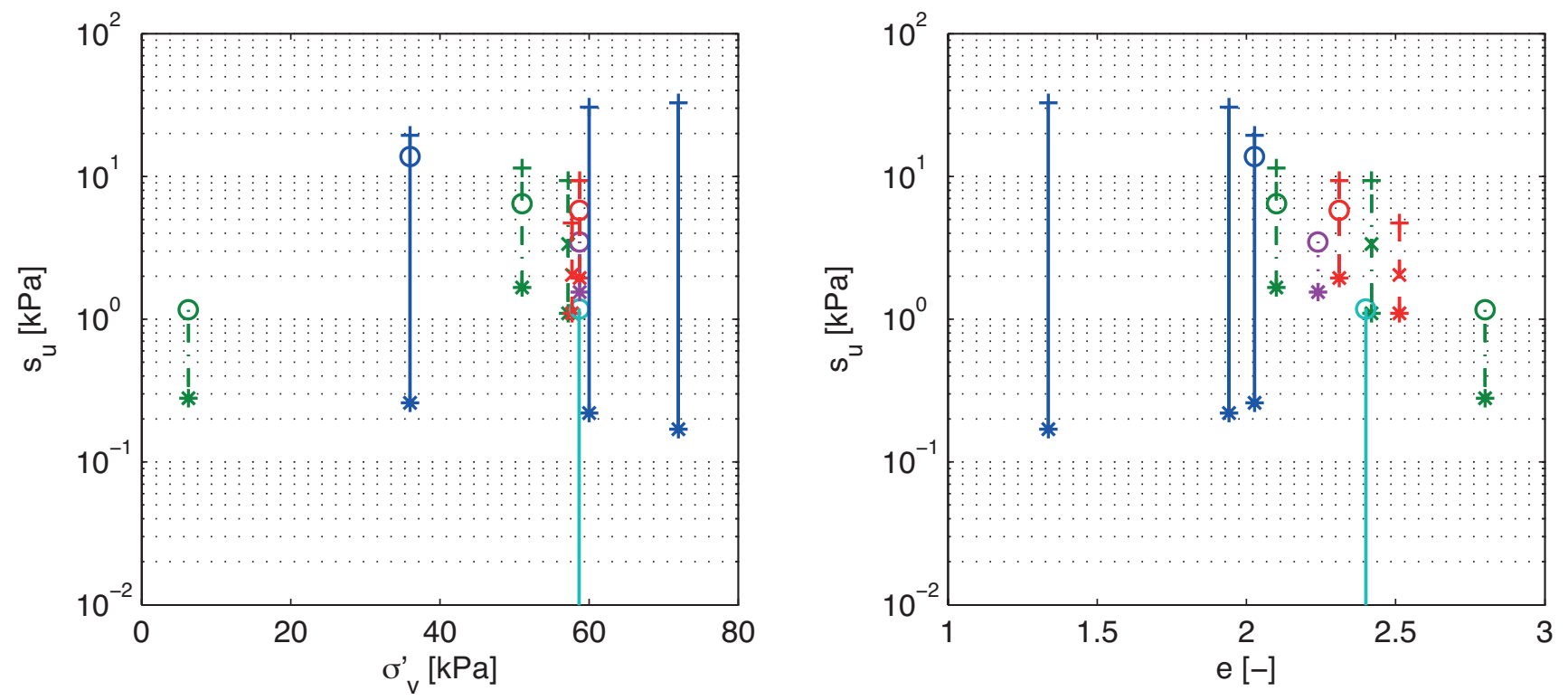

\begin{tabular}{|c|c|c|c|c|c|c|c|}
\hline+ & Undisturbed, fall cone & 0 & Undisturbed, vane & $x$ & Remoulded, fall cone & * & Remoulded, vane \\
\hline & $\begin{array}{l}\text { Original } \\
\text { material }\end{array}$ & & uted & ned' & $\begin{array}{l}\text { Leached, } \\
\text { hydraulic head }\end{array}$ & & $\begin{array}{l}\text { Leached, } \\
\text { diffusion }\end{array}$ \\
\hline
\end{tabular}

Fig. 4. Effective stress and void ratio versus strength for original and reconstituted samples. The original samples are assumed to be normally consolidated, and stresses are calculated based on known depth and measured density. The remoulded strength of the leached sample could not be accurately measured, and is lower that $0.1 \mathrm{kPa}$. 


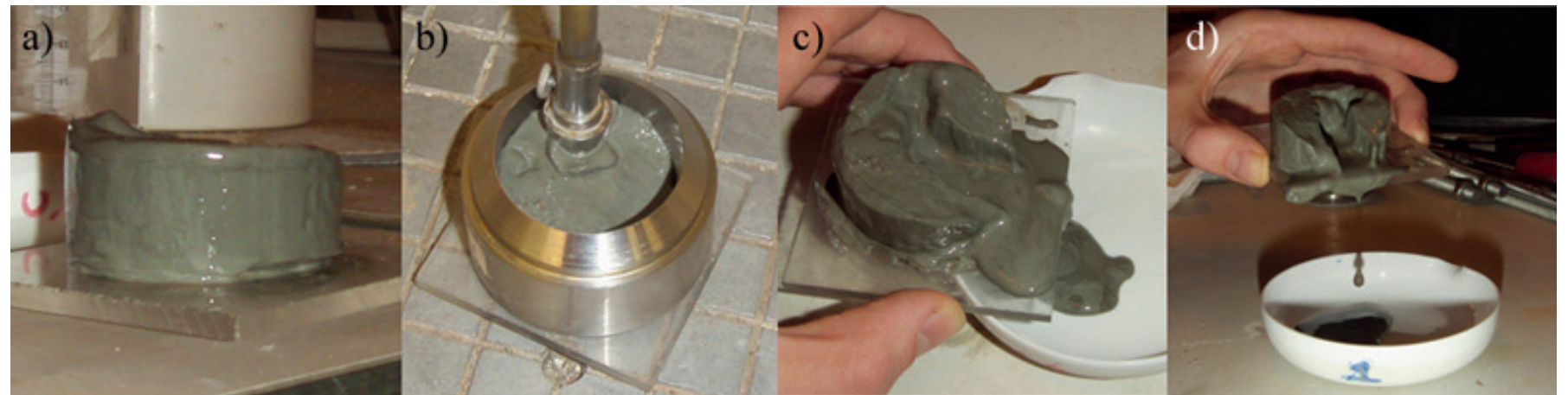

Fig. 5. Pictures of the sample leached with demineralized water. a) sample after extraction from tube, b) attempted strength measurement with fall cone. Note the disturbance around the cone, c) and d) liquefaction of sample after disturbance. 